\title{
Work and family conflict analysis of female entrepreneurs in Turkey and classification with rough set theory
}

\author{
Gülgönül Bozoğlu Batı (D) ${ }^{1 凶} \&$ İsmail Hakkı Armutlulu ${ }^{2}$
}

Entrepreneurs face numerous challenges and experience conflicts in their daily lives. However, it is clear that female entrepreneurs have more conflicts than male ones due to society's perception of women and various expectations from them, and consequently, these conflicts affect women's investment decisions. In this study, especially conflict levels of female entrepreneurs at work and in family have been investigated. Also, this study dwells upon how the roles that female entrepreneurs play in family and at work shape their investment plans and how the conflicts they experience affect their investment decisions. In this study, a total of 348 face-to-face interviews with female entrepreneurs, from the four major cities of the most economically developed region of Turkey, have been conducted, and various questions about demographic characteristics, business characteristics, entrepreneurship densities, business, and family conflict situations and investment plans have been asked. The obtained data has been analyzed and classified via rough set theory. The correlative relationship between conflict and investment decision has also been demonstrated. This paper contributes to the extant literature - in which there is an essential gap relating to female entrepreneurs in Turkey - by describing their status, conflict levels and investment decisions with quantitative data. The study presents a new perspective on the classification of female entrepreneurs with a rough set theory which is considered to be superior to other classification methods in terms of classifying objects with the same characteristics according to different decision situations.

\footnotetext{
${ }^{1}$ Yalova University, Yalova, Turkey. ${ }^{2}$ Marmara University, İstanbul, Turkey. ${ }^{\varpi_{e}}$ email: gulgonul@yalova.edu.tr
} 


\section{Introduction}

ntrepreneurship has become a concept that attracts interest in academia, public and private sectors, since it is a sign of economic development and prosperity for individuals as well as society. The relationship between entrepreneurship and economic development is also scientifically accepted (Carree and Thurink, 2003; Van Praag and Versloot, 2007; Kauffman Foundation, 2012).

Entrepreneurship requires decision-making in an environment of uncertainty. The real-life modeling is too complex to be solved by the two-valued logic of mathematics, because there are many options where a situation may or may not be a member of an event. Rough set theory takes a different approach to uncertainty. While forming rough sets, objects are on one side and properties of objects on the other. Objects are grouped with combinations of these properties (Armutlulu, 2014). Considering whether objects are a member of a situation or not, the uncertainty of no boundary is encountered. In rough set theory, no boundary can be determined by using the boundary region of objects. A set (cluster) which has a non-empty boundary region is called a rough set (Pawlak, 1982). If our knowledge of a set is insufficient to precisely define it, then the boundary set does not equal to an empty set. Frege states that concepts without sharp boundaries correspond to an area without sharp boundaries (Pawlak, 1998). In the rough set theory, which is a special approach to the vagueness of Frege, topological operations, which are known as approximations, are performed. Upper and lower approximations to the set are determined. In approximations, which are expressed with our knowledge about objects, the approximations from the low are exactly the composition of the information particles contained within the set. The approximations from the up, however, are made up of aggregation of the particles which have non-empty intersection sets, and finally boundary region is obtained through the difference between approximations from the up and the low. In this sense, some information regarding memberships can be attained.

Female entrepreneurs do not only have obligations to cope with investment risk. But they are also to fulfill their familyrelated responsibilities simultaneously. The purpose of the study is to determine the conflict levels of female entrepreneurs in the face of the responsibilities imposed both by the family and the enterprise itself, to exhibit how significant these responsibilities on their investment decisions, and to see how conflict level, which emerges as a result of family and enterprise-related responsibilities, affects female entrepreneurs' investments. Research questions can be summarized as follows:

RQ1: Are the responsibilities of female entrepreneurs in both business and family decisive for conflict that they experience?

RQ2: Are the responsibilities of Female entrepreneurs in both business and family decisive for their investment decision?

RQ3: What is the relationship between conflict level that they experience both in business and family and their investment decision?

\section{Literature review}

Female entrepreneurship. Women's priority task was working in or around the house as a wife or a mother throughout the history. In case they worked out of the house, they always helped their husbands as unpaid worker. Women started to work in factories as a worker in Europe in the 18th and 19th centuries when the "Industrial Age" began. Women participation to the work life was limited and remained that way until the Second World War. Women employment was seen one of two ways during the war: (1) They worked in factories in order to sustain production on behalf of their husband, father or brother (Smith-Hunter, 2006;
Nayır, 2008). (2) They worked as a nurse in hospitals for the treatment of the soldiers who got injured during the war (SmithHunter, 2006).

Women's change was distinctively different in Turkey from Europe. The Republic of Turkey was founded in 1923 as a democratic country. Based on secularism, nationalism, and modernization, many reforms were made on social, economic, political, and linguistic areas between 1923 and 1934. This predominantly Muslim country gave equal rights to both men and women in each segment of life. Since then, women have appeared more not only in women-based works but also men-based works.

Technological developments in the 1970s and 1980s facilitated home-based works and these developments directed liberalized women, to income generating activities. As a result, entrepreneurship was seen as an appropriate work area for women (Karadal and Kaygin, 2013).

Entrepreneurial activity associated with women and men and the behaviors and roles deemed appropriate for members of each sex (Jennings and Brush, 2013). That is the reason why entrepreneurship is addressed based on gender.

Although the first studies on entrepreneurship date back to the 1930s, Schwartz wrote the first scientific publication on the subject from a woman's perspective. The first policy report was written in the US in 1979 under the name of 'The Bottom Line: Unequal Enterprise in America'. The first conference presentation was made by Hisrich and O'Brien in 1981, and the first academic book was published by Goffee and Scase in 1985 (Jennings and Brush, 2013).

Schwartz's article (1976), in which she compared the motivations of female and male entrepreneurs, their desire to succeed and job satisfaction, was followed by works written by Hisrich and Brush in the 1980s. In their articles, they examined the management skills of female entrepreneurs (1984), made comparisons of female and minority entrepreneurs (1985), investigated the process of starting a business, management, and monetary situation (1986), and published the comments and experiences of 468 women, thus demonstrating the challenges that women face in the field of entrepreneurship and the characteristics that they should develop (1987). Until the end of the 1980s, studies tended to define and conceptualize the subject, and their aim was to determine the characteristics of female entrepreneurs (Casson et al., 2006).

In the 1990s, research topics focused on the reasons why women choose entrepreneurship, the growth and development of female entrepreneurs, and how the characteristics of countries affect women entrepreneurship (Casson et al., 2006). As a result of the studies carried out in the late 1990s and the early 2000s, women's entrepreneurship sub-field achieved some success. These achievements were described by Bruyat and Julian (2000), Katz (2003), and Welter and Smallbone (2011). In 1997, the academic journal of Entrepreneurship and Regional Development was dedicated for the first time to this subject. The first private policy conference was held in 1998 by the Organization for Economic Co-operation and Development (OECD) and in 2003, "International Diana", an academic conference was held. In 2009, a specifically dedicated journal on this very subject; the International Journal of Gender and Entrepreneurship started its publication life (Jennings and Brush, 2013).

To date, foundational questions on female entrepreneurship is related to four main areas (Jennings and Brush, 2013), and the comprehensive answers for each of these questions are summarized in Table 1 in the light of cumulative experimental evidence.

Due to gender-based entrepreneurship studies that are summarized in the Table 1, entrepreneurship and entrepreneurial activities for each gender differ. 
Table 1 Foundational questions, overarching answers and specific illustrative findings within women's entrepreneurship research.

\section{Foundational question}

Are women and men equally likely to engaged in entrepreneurship?

Do male and female entrepreneurs tend to differ with respect to financial resource acquisition?

Do female and male entrepreneurs tend to enact different strategic, organizational and managerial practices within their firms?

Do female-led and male-led firms perform equally well?

\section{Overarching answer}

No. Worldwide, women are less likely to be involved in various forms of entrepreneurial activity.

Primarily yes. In general, businesses headed by women tend to be financed at a lower level and by different means than those headed by men.

Yes, and no: Although notable differences exist with respect to the strategies of female and male-led firms, few organizational and managerial differences have been documented to date.

Primarily no: According to many standard economic indicators, businesses headed by women do not perform as well, on average, as those headed by men; on other indicators, however, this is not the case.

Source: Jennings and Brush (2013, pp. 668-669)

Out of the scope of the questions examined, studies have revealed that men and women resemble each other in terms of motivations, values, and expectations (Kuratko and Hodgetts, 1995; Hisrich and Peters, 2002). However, it is found that purposes of starting a new business, personal characteristics, such as risk taking and self-confidence, communication, and networking skills, and their preferred fields may differ by gender (Hisrich and Peters, 2002; Hisrich and Ozturk, 1999; Brush et al., 2004).

Although female entrepreneurs exhibit different characteristics, they have common problems which arise from their gender and these problems effect their job performances. These problems have been subject to many studies in local, national, and international level and comparisons on personal, behavioral, social, instinctual perspectives with their male counterparts have been made. By looking at the previous research conducted, it can be seen that female entrepreneurs' performance levels and their growth and profitability goals are lower when compared with male ones (DuRietz and Henrekson, 2000; Sexton, 1989).

Business and family conflict. Work and family are the two inseparable parts of life. Responsibilities assumed at work and in the family are important roles that a person undertakes in life. Individuals with limited time and energy in fulfilling their responsibilities in work and at family may occasionally have to interrupt one of these two roles.

Work and family conflict is a form of conflict among roles and this conflict may occur due to role pressure that emerges as a result of the reciprocal contradiction of these two roles. Suppose an individual experiences some difficulties in performing her family-related role when fulfilling her work-related tasks, it is called work-family conflict, if the contrast is the case, then it is called family-work conflict (Greenhaus and Beutell, 1985). This is experienced due to the fact that both work and family-related roles emerge simultaneously (Parasuraman and Simmers, 2001). Thus, this conflict makes an individual unhappy and inefficient, both at work and at home as she assumes that she cannot fulfill her roles properly (Hill, 2005).

It is known that working women experience more conflict and are adversely affected, since they assume more responsibility at home due to the social and cultural structure (Gutek et al., 1991; Ahmad and Skitmore, 2003; Hill, 2005; Van Veldhoven and Beijer, 2012). According to a G20 study, the most important problem of working women is the work-family balance (Hutt, 2015). In order to balance the roles, they undertake at work and in the family, women start an autonomous and independent business for themselves or step into entrepreneurship that gives them flexibility in life (Agarwal and Lenka, 2015; McGowan et al.,
2012; Winn, 2004; Jennings and Brush, 2013; Caputo and Dolinsky, 1998; Gatewood et al., 1995). Therefore, it is meaningful to look at women's entrepreneurship in terms of family. The family perspective in entrepreneurship means that researchers should include the family dimension in conceptualization and modeling, sampling and analyzing, and sense-making and interpretation (Aldrich and Cliff, 2003).

Business and family conflict arises in two ways: it examined as work-family and family-work conflict (Frone et al., 1997; Greenhaus and Beutell, 1985; Carlson et al., 2000). Greenhaus and Beutell stated that these conflicts occurred in three forms as time, strain, and behavior. These forms can be summarized as time devoted to one role makes it difficult to fulfill requirements of another role; strain produced by one role makes it difficult to fulfill requirements of another role and behavior required in one role makes it difficult to fulfill requirements of another role (1985).

Business-family conflict occurs as a result of interaction. Although business-family and family-business conflicts separate from each other, they are interrelated (Byron, 2005). Because one role affects the other one constantly, conflicts may occur (Frone et al., 1992a). Therefore, looking this issue from both sides can give more descriptive results.

Business-family conflict occurs as a result of work effect on family. Responsibilities of work affects person's family life. It emerges when participating to business activity blocks to participating in a family activity, or business stress influence entrepreneurs' behaviors in family negatively (Greenhaus and Powell, 2002; Frone Russell and Cooper, 1992a, 1992b). Factors such as intensity and flexibility of work hours, dedication, stress in work (Byron, 2005) affect workers psychology (Frone et al., 1997), health (Schmitt et al., 1980) and general satisfaction of life (Bedian et al., 1988; Parasuraman et al., 1992).

Frone et al. (1992b) find that business-family conflict occurs three times more than family-business conflict for both genders. In a similar manner, Ufuk and Özgen (2001) conducted their research on female entrepreneurs' conflict level in the capital city of Turkey and they found out that female entrepreneurs, who are married, suffer from conflict and being entrepreneur affects negatively their family life. Also in our study, work-family conflict is higher than family-business conflict. Also, a study that was conducted in Turkey, indicates that individuals stated that their work effect to family was more than family effect to work (Aycan, 2013).

Family-business conflict occurs as family life interference in work life. It emerges when participating in a family activity blocks to participating in a business activity or, when family stress affects negatively business performance (Greenhaus and Powell, 2002; Frone et al., 1992a, 1992b). Factors such as family support, stress 
in family, number of children, age of the smallest child, spouse employment, marital status, family relationships, allocated time for out of work can affect family-business conflict (Byron, 2005; Eby et al., 2005). The conflict that arises from negative effect of family to business have a strong relationship with job satisfaction (Netemeyer et al., 1996), being late to business, not going to business (Eagle et al., 1998) and lack of performance (Frone et al., 1997; Bagger and Li, 2012).

Because of responsibilities that women have in family, they live family-business interaction more than men. Men have stronger dedication and therefore, they live business-family interaction more than women (Eagle et al., 1997). Family-business conflict is more decisive on women's health and happiness than business-family conflict (Noor, 2004).

Investment decision. Joseph Schumpeter (1947), said: “we should recognize the importance of, and systematically inquire into, entrepreneurship as a factor of economic growth". Economic growth is affected by physical environment, social organization, policy, technology, national spirit, and human material (Schumpeter, 1947). Small and medium size businesses form basis of countries' economies. Business growth always has a critical importance in entrepreneurship and venture growth. Therefore, it should be taken as a dependent factor (Delmar, 1996). Because it creates employment and increases prosperity level (Pistrui and Lucia, 2003).

Multidimensional structure of a planned growth indicates in psychology, sociology, economy, and business administration disciplines. Psychology examines individuals' behaviors, attitudes, beliefs, and motives. Sociology points out formal (peer, colleague) and informal (family) communication networks' and groups' role and relations in the cover of culture. Economy researches obstacles, barriers, support structures of environmental infrastructure for growth. Discipline of business administration indicates expansion, investment, upgrade operations, or production (Pistrui, 1999). Entrepreneurial intensity of individual is evaluated in framework of the psychological factors. In this study, entrepreneurial intensity is used as a scale. Because, it is found out that there is a strong relationship between entrepreneurial intensity and growth intention and also it is found that high growth entrepreneurs have more entrepreneurial intensity (Gundry and Welsch, 2001).

It is possible to discuss business growth which are directed by women in four dimensions: individual, concept of enterprise, firm resources, and institutional financial resources. In addition, growth potential can be affected by business sector and general economic condition of the country. In frame of the proposed growth, individual is evaluated in the context of family. It is thought that demographic and personal skills are effective on investment growth. Concept of enterprise is determined with business potential and growth goal (Brush et al., 2010). In the framework of this research female entrepreneurs' roles in both family and business with investment decision is handled together by using rough set analysis.

Many studies have been done which examine female and male entrepreneurs' attitudes towards growth. Some of these studies indicate that females prefer to keep their business in small size (Cliff, 1998; Orser and Hogarth-Scott, 2002). Female entrepreneurs' can be less likely to express high growth intentions for their ventures than men. But for nascent entrepreneurs, it is found that both for male and female, high growth intention is not as important as career reasons (Davis and Shaver, 2012).

Conflict effect on investment decision. Women's family and household responsibilities are known to have an impact on their investment decisions about emerging or existing opportunities as well as on their access to resources (Carter and Ram, 2003; Aldrich and Cliff, 2003; Türkonfed, 2014).

A female entrepreneur's business growth goals might be affected intentionally or unintentionally due to mostly conflicting demands of her work and home-related roles. Female entrepreneurs stated that they are comfortable in the company that they can control, they spend an acceptable amount of time and energy and they can balance their work and personal lives in this way (Cliff, 1998). Growing the business may not be very valuable among the steps of the circle of life. Therefore, it is a choice not to grow the business (Morris et al., 2006).

In women's entrepreneurship research, it is almost axiom that entrepreneurial activity is embedded in family systems. Entrepreneurship decisions, processes, and outcomes not only affect family-level factors, but also they affect the family. A considerable number of female entrepreneurs, if not the most, do not see business as a separate economic asset, but rather as something that is wrapped around other aspects of their lives, especially family relationships and responsibilities (Jennings and Brush, 2013).

It was found that female entrepreneurs experience less work-family conflicts than their colleagues who are not selfemployed as themselves (Rembulan et al., 2017; Thebaud, 2015). Since business ownership provides high autonomy and flexibility in work plan, working hours and physical workplace selection (Thebaud, 2015).

Women with equal education opportunities (as men) do not make similar investment decisions as their male counterparts in their entrepreneurship journey, and this can be attributed to the fact that women value growth, and women's priority of the family in life is an important parameter of this.

Relational analyses and/or analyses comparing two different groups have been included in this study. For the first time, rough set theory was used as a method in the classification of female entrepreneurs.

Rough set theory is superior to other classification methods in terms of classifying objects with the same characteristics according to different decision situations, as discussed in detail in the "Methodology" section. In this sense, the study presents a new perspective on the classification of female entrepreneurs.

\section{Methodology}

Rough set analysis. In general terms, a set can be defined as a collection of objects with similar characteristics. The set is the basis of mathematics. The elements of the set are evaluated in the dilemma of being or not being a member of classical set theory. However, there are a wide variety of options between belonging and not belonging to a community in real life. For this reason, real-life modeling cannot be solved by the two-valued logic of mathematics. Rough set theory is an approach to vagueness. In the rough set theory that was put forward by Pawlak in 1982, vagueness comes into question with elements in the border region of the set (Pawlak, 1982). Vagueness is based on gradual notations of categories in the natural language and refers to sets that are not strictly limited (Tripathy, 2009). Pawlak proved in 1991 that the theory was a mathematical tool for analyzing the ambiguity of objects. In his proof, he basically, defines the set of objects along with its properties, determines the approximations and the dependencies between properties and exhibits the formation of decision rules (Pawlak, 1991).

Indiscernibility, like vagueness, is the obvious side of missing information. In the basic idea of the rough set theory, it is based on the indiscernibility principle where each object is associated with a certain amount of information and the object can only be 
expressed through some information obtained. Thus, objects that carry the same or similar information may not be distinguished from the information we can access. Non-distinguishable patterns are called the element set or information granule (building block) (Jian et al., 2011). The indistinguishable elements form the boundary set and elements at the boundary are not included in the set itself or its complement classes. Rough set theory is a new mathematical approach to uncertainty and vagueness (Pawlak, 2000). It can deal with incomplete or missing information (Pawlak, 2004). With this approach, the reduction of data, the determination of dependencies, estimation of data significance level, the formation of decision algorithms, approximate classification of data, identification of similarities, differences and patterns, and revelation of cause-effect relations are provided (Pawlak and Slowinski, 1994).

In rough set theory, the vagueness is expressed by the boundary region of a set. The concept of rough set is generally defined by the topological processes namely; interior and closure, and these are called approximations (Pawlak, 2004).

In many decision-making problems, we need to assess the information that we have. While making decisions, objects with a certain set of properties lead to same decision outcomes, whereas objects with the same properties lead to different decision outcomes.

Objects with the same properties are indiscernible and form a block. These blocks are called basic granule of knowledge about the universe. It is possible to treat these granules as the 'atom' of information and they are called elementary sets (concepts). Any union of elementary sets is referred to as crisp (precise) setsotherwise the set is rough (imprecise, vague) (Pawlak, 2004).

In this case, it is difficult to claim that certain properties exhibit certain decision variables. The information we have about the features may be insufficient to reveal the decision variable. In such a case, by using the rough set theory, we can show the distance of the objects to the decision set with the help of approximations (Pawlak, 1997).

In the scope of the study, a five-point likert scale is used. However, in the rough set analysis, the intensity of entrepreneurship, investment decisions and conflict levels were reduced to three as low, medium, and high for ease of use. To calculate, the sum of the answers given to each question in the related scale was noted. The score scale was calculated over the total score and female entrepreneurs with low scores was classified as 'low', those with high scores as 'high', and those with average scores as 'medium'.

In this study, first, granules were formed, then, boundary sets were determined with lower and upper approximations of decision sets, and finally, memberships of the objects (female entrepreneurs) in the decision sets were calculated.

Lower and upper approximation sets, boundary set and granules. $C(x)$ refers to the equivalence class of $C$ defined by $x$ elements in the universe set. If we have incomplete information about a universe $(U)$, we can say with absolute certainty that it is indiscernible. The equivalence classes of the indiscernible relationship are called granules, which represent the basic part of the information that can be comprehended in relation to $C$. Granules can be detected with the help of $C$. In this respect, we can observe objects that are different from each other, however, we can reason with as many pieces of information as we can obtain (Pawlak, 2004). In our study, there are 226 granules with the same condition properties. The condition properties were limited to the entrepreneurial role (entrepreneurial time, partner's activity status, entrepreneurial intensity) and family role (marital status, age of youngest child, and educational status).
It is also possible to show approximations on a set. The lower approximation consists entirely of granules within the set. The upper approximation, on the other hand, consists of all granules whose intersection is not an empty set. The boundary region shows the difference between these two approximations (Pagliani and Chakraborty, 2008). According to our 226-granule research model, the memberships of work-family conflict, family-work conflict and investment decision sets have been shown on lower/ upper approximation sets. In this context, sets that are located in the boundary region have been calculated. By doing so, this study aims to identify whether female entrepreneurs are within, outside, or at the boundary region of the aforementioned decision sets according to their characteristics.

Rough set can be characterized numerically by the following coefficient:

$$
\alpha_{\mathrm{C}}(X)=\frac{\left|C_{*}(X)\right|}{C^{*}(X)}
$$

Accuracy of approximation of a rough set can be calculated with the coefficient of $\alpha_{\mathrm{C}}(X)$ via $C$ relation (provided $X \neq \varnothing$ ):

It is evident that $0 \leq \alpha_{\mathrm{C}}(X) \leq 1$.

If $\alpha_{\mathrm{C}}(X)=1$, then $X$ is precise with respect to $C$.

If $\alpha_{C}(X)<1$, then $X$ is rough with respect to $C$ (Pawlak, 1997).

The vagueness or preciseness of the decision sets was calculated (low, medium, and high levels of the decision sets).

Membership degrees. Rough sets can also be defined by membership functions (Pawlak and Slowinski, 1994). The degree of membership of the rough set is determined by the ratio of the number of elements at the intersection of the granule to which the object belongs, and the number of elements of the granule.

The $\mu_{X}^{\mathrm{C}}(x)$ membership function is a conditional probability (Provided $C(x)$ is a condition), and it indicates $X$ 's degree of certainty of the belonging to the defined set $X$.

It is also possible to benefit from membership functions when defining the lower and upper approximations and the boundary region.

$$
\begin{gathered}
C_{*}(X)=\left\{x \in U \mid \mu_{X}^{\mathrm{C}}(x)=1\right\} \\
C^{*}(X)=\left\{x \in U \mid \mu_{X}^{\mathrm{C}}(x)>0\right\} \\
\operatorname{BN}_{\mathrm{C}}(X)=\left\{x \in U \mid 0<\mu_{X}^{\mathrm{C}}(x)<1\right\}
\end{gathered}
$$

\section{Application}

In this study, the conflict and investment plans of 348 female entrepreneurs working in Turkey's four different provinces (Istanbul, Kocaeli, Bursa, and Yalova), which have the highest economic contribution to Turkey and the least gender inequality, have been analyzed and the relation of the conflict with the investment decision has been measured.

The research model consists of three dimensions and is presented in Fig. 1.

1. To identify the roles and responsibilities of female entrepreneurs at home and in work and to measure the conflict levels that they may experience at home and in workplace.

2. To measure the impact of these roles and responsibilities on investment decision.

3. To measure the relationship between their level of conflict and investment decisions.

The relations examined in the first stage are in two groups. In the first group, some requirements of entrepreneurship role, such as the entrepreneurial role, the activity status of the partner, the intensity of the entrepreneur are discussed. In the second group, some requirements of family role such as the marital status, the age and education of the youngest child, and the conflict between 


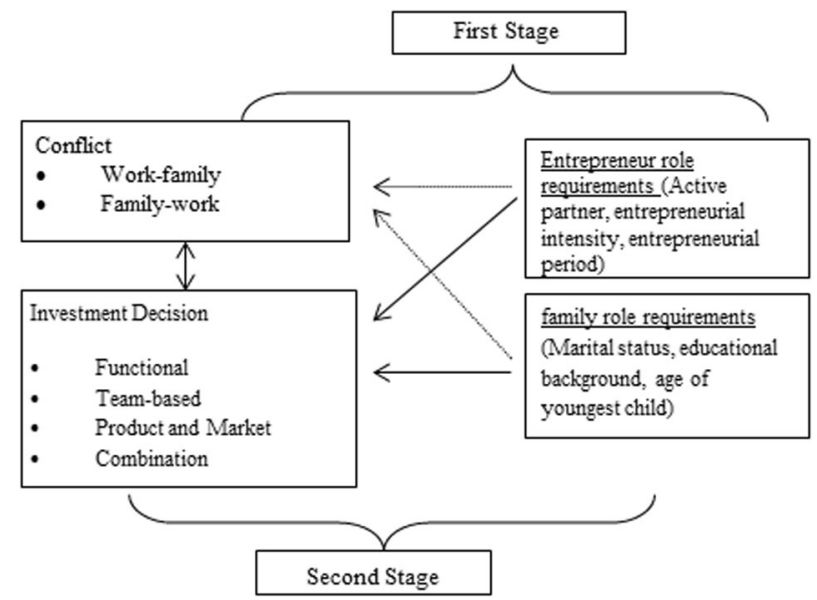

Fig. 1 Research model.

work-family and family-work are considered. Boundary sets for roles and responsibilities of both levels were calculated via rough set analysis by the lower and upper approximations to the conflict level, which is the decision set of each object. The degree of membership of the objects to the set was measured.

In the second stage, entrepreneur role requirements and family role requirements and their relationship on investment decision were examined. Rough set analysis was used as the method.

The lower/upper approximations, boundary sets and membership degrees of the investment decision that was compiled at the "low", "medium", and "high" levels of the responsibilities of entrepreneur and family roles were calculated.

Finally, the relationship between investment decision and work-family/family-work conflicts was examined. In this stage, correlation analysis was conducted. Investment decision was dealt with in the following four sub-groups (Gundry and Welsch, 2001).

1. New means of production purchase plan (functional),

2. Plans to train existing personnel and/or recruit new staff (team based),

3. Product development and plans to tap into new markets (product and market),

4. Plans on issues not included in the above three groups (combinations).

Rough sets. In order to establish rough sets following steps are implemented:

Decision sets. Decision sets are prepared for two stages. In the first stage, decision sets are work-family and family-work conflicts, whereas in the second stage, decision sets are functional, teambased, product-market, and combination sub-dimensions of the investment decision.

Decision sets for the First Stage: Work-family $(X)$ and family-work $(Y)$ conflicts decision sets that were formed in relation to decision columns, were classified as low, medium, and high.

There are a total of 112 female entrepreneurs with high, 88 with medium and 148 with low work-family conflict levels.

There are a total of 26 female entrepreneurs with high, 108 with medium and 214 with low family-work conflict levels.

Granules. When we arrange the following Table 2 with a classification according to condition characteristics, which results in high, medium, and low or 3, 2, 1 decision-characteristics in

\begin{tabular}{|l|lllllll|}
\hline \multicolumn{1}{l}{ Table 2 Calculation of granules of the first stage. } \\
$\qquad$\begin{tabular}{llllllll} 
\\
\multicolumn{10}{c|}{ C1 } & C2 & C3 & C4 & C5 & C6 & D \\
\hline 1162 & 1 & 2 & 2 & 2 & 0 & 4 & 1 \\
289 & 1 & 3 & 2 & 2 & 0 & 4 & 2 \\
3 & 1 & 3 & 2 & 2 & 0 & 2 & 2 \\
$\vdots$ & $\vdots$ & $\vdots$ & $\vdots$ & $\vdots$ & $\vdots$ & $\vdots$ & $\vdots$ \\
$43,123,204,216,250,348$ & 1 & 1 & 2 & 1 & 3 & 4 & 3 \\
$\vdots$ & $\vdots$ & $\vdots$ & $\vdots$ & $\vdots$ & $\vdots$ & $\vdots$ & $\vdots$ \\
\hline
\end{tabular}
\end{tabular}

work-family conflict, we call each row of this table a granule. Our condition features have been arranged in the following table including entrepreneurial time $(\mathrm{C} 1)$, presence of an active partner (C2), entrepreneur density (C3), marital status (C4), age of youngest child (C5), and educational status of the entrepreneur (C6) (see Table 2).

As shown in Table 2, entrepreneurs with the same characteristics form a single granule. These entrepreneurs are classified together. A total of 226 granules can be seen. The large number of granules, the fact that largest granule is consisting of 9 female entrepreneurs, the fact that 167 granules have a single-member, indicate a diversity of features.

Decision sets for the second stage. In the second stage, our condition characteristics are the same. The granules are therefore the same. Investment decisions will be discussed in the rough set approach as decision property (D). Since we will examine the investment decision under 4 sub-factors, 12 rough clusters are defined in which we examine low, medium and high level investment trends for 4 different groups namely; functional, team-based, product and market, and combination.

The number of female entrepreneurs with a low functional investment decision $\left(F_{1}\right)$ is 76 . The number of female entrepreneurs with a medium functional investment decision $\left(F_{2}\right)$ is 97 . The number of female entrepreneurs with a high functional investment decision $\left(F_{3}\right)$ is 175 .

The number of female entrepreneurs $\left(T B_{1}\right)$ who consider teambased investment decision at a low level is 110 . There are 104 female entrepreneurs $\left(T B_{2}\right)$ with a medium-level team-based investment decision. There are 134 female entrepreneurs with high level of team-based $\left(T B_{3}\right)$ investment decisions.

The number of female entrepreneurs who want to keep their investment decision low on product and market basis $\left(P M_{1}\right)$ is 112. There are 105 female entrepreneurs whose product and market-based investment decision is medium $\left(P M_{2}\right)$. The number of female entrepreneurs $\left(P M_{3}\right)$ considering a high level of product and market-based investment decision is 131 .

The number of female entrepreneurs $\left(C_{1}\right)$ who intend to keep the combination investment decision at a low level is 116 . The number of female entrepreneurs who want to invest in a medium level combination $\left(C_{2}\right)$ is 112 . Within the combination factor, the number of female entrepreneurs who have made high investment decisions $\left(C_{3}\right)$ is 120 .

The classification of lower/upper approximations and borderline. The calculations were made for both stages of the research model and presented as two separate titles.

First stage $-X, Y$ sets lower/upper approximations and boundary sets. In low $\left(X_{1}\right)$, medium $\left(X_{2}\right)$, and high $\left(X_{3}\right)$ work-family conflicts, in order to determine lower/upper approximations of the set and the boundary sets, every granule is controlled. This control is done in order to find out whether a conflict level is a subset of their respective sets. (For the low conflict level $\left(X_{1}\right)$, for 


\begin{tabular}{|c|c|c|c|c|c|}
\hline \multirow[b]{2}{*}{ Work-family C. } & \multicolumn{5}{|c|}{ Element number } \\
\hline & $C_{\star}$ & $C^{\star}$ & $\mathbf{B N}_{\mathbf{C}}$ & Excluded ones & $\alpha_{\mathrm{c}}$ \\
\hline$X_{1}$ low & 98 & 209 & 111 & 139 & 0.47 \\
\hline$x_{2}$ medium & 57 & 135 & 78 & 156 & 0.42 \\
\hline$x_{3}$ high & 68 & 162 & 94 & 118 & 0.42 \\
\hline Family-work C. & $\boldsymbol{C}_{\star}$ & $C^{\star}$ & $\mathbf{B N}_{\mathbf{C}}$ & Excluded ones & $\alpha_{\mathrm{c}}$ \\
\hline$Y_{1}$ low & 134 & 261 & 95 & 119 & 0.51 \\
\hline$Y_{2}$ medium & 62 & 165 & 103 & 183 & 0.38 \\
\hline$Y_{3}$ high & 12 & 67 & 55 & 281 & 0.18 \\
\hline
\end{tabular}

the medium level $\left(X_{2}\right)$, and for the high level $\left(X_{3}\right)$.) For family-work conflicts, the lower and upper approximation sets, low $\left(Y_{1}\right)$, medium $\left(Y_{2}\right)$, and high $\left(Y_{3}\right)$, and the boundary region are determined.

The rule for the lower approximation:

$$
C_{*}(X)=\{x \in U \mid C(x) \subseteq X\}
$$

The rule for the upper approximation:

$$
C^{*}(X)=\{x \in U \mid C(x) \cap X \neq \emptyset\}
$$

The lower approximation set to set $X_{1}$ of $C$ set is the combination of granules that are subsets. The lower approximation set has 98 elements. The upper approximation set is the intersection of the set $X_{1}$ and the non-empty sets. The upper approximation set has 209 elements. For the low conflict level $X_{1}$, the lower and upper approximation sets are not the same. The boundary set is shown as follows:

$$
\mathrm{BN}_{C}\left(X_{1}\right)=C^{*}\left(X_{1}\right)-C_{*}\left(X_{1}\right)
$$

When $C *\left(X_{1}\right) \neq \varnothing$ and $C^{*}\left(X_{1}\right) \neq U$, the $X_{1}$ set can be roughly defined in relation to the $C$.

Since the lower and upper approximations are not the same, it can be claimed that $C^{*}\left(X_{1}\right) \neq C_{*}\left(X_{1}\right)$ boundary set exists. The boundary set is a set consisting of 111 elements.

The certainty of numerical approximation of a rough set is the ratio of the cardinality of the lower approximation to the cardinality of the upper approximation:

$$
\begin{gathered}
\alpha_{\mathrm{c}}\left(X_{1}\right)=\frac{\left|C_{*}\left(X_{1}\right)\right|}{\left|C^{*}\left(X_{1}\right)\right|} \\
\alpha_{\mathrm{c}}\left(X_{1}\right)=\frac{98}{209}=0.4711
\end{gathered}
$$

Table 3 shows the lower and upper approximations and boundary sets of the two dimensions of conflict according to the low, medium, and high conflict levels, and the approximation accuracy of the calculations.

Looking at the table above, it can be seen that the work-family conflict and the family-work conflict are low for female entrepreneurs. The lower approximation, that is, the number of granules in the set is definitely higher for the "low" category of both types of conflict. When two levels of conflict are compared, it is possible to say that family-work conflict is experienced even lower. The upper approximation shows the granules whose intersection with the set is not empty. In the upper approximation, granules belonging to the "low" conflict level are higher for both conflict levels.

Second stage-lower/upper approximations of PM, F, TB, C and

\begin{tabular}{|c|c|c|c|c|c|}
\hline \multirow{2}{*}{$\begin{array}{l}\text { Investment decision } \\
\text { Product and market }\end{array}$} & \multicolumn{5}{|c|}{ Element number } \\
\hline & $\boldsymbol{C}_{\star}$ & $C^{\star}$ & $\mathbf{B N}_{\mathbf{C}}$ & Excluded ones & $\alpha_{\mathrm{c}}$ \\
\hline$P M_{1}:$ Low & 61 & 185 & 124 & 163 & 0.33 \\
\hline$P M_{2}:$ Medium & 59 & 184 & 125 & 164 & 0.32 \\
\hline$P M_{3}:$ High & 76 & 200 & 124 & 148 & 0.38 \\
\hline Functional & $\boldsymbol{C}_{\star}$ & $C^{\star}$ & $\mathbf{B N}_{\mathbf{C}}$ & Excluded ones & $\alpha_{\mathrm{c}}$ \\
\hline$F_{1}:$ Low & 42 & 128 & 86 & 220 & 0.33 \\
\hline$F_{2}:$ Medium & 56 & 181 & 125 & 167 & 0.31 \\
\hline$F_{3}:$ High & 106 & 237 & 131 & 111 & 0.45 \\
\hline Team-based & $\boldsymbol{C}_{\star}$ & C & $\mathbf{B N}_{\mathbf{C}}$ & Excluded ones & $\alpha_{c}$ \\
\hline$T B_{1}:$ Low & 64 & 172 & 108 & 108 & 0.37 \\
\hline$T B_{2}:$ Medium & 59 & 169 & 110 & 110 & 0.35 \\
\hline$T B_{3}:$ High & 82 & 207 & 124 & 124 & 0.40 \\
\hline Combination & $\boldsymbol{C}_{\star}$ & C & $\mathbf{B N}_{\mathbf{C}}$ & Excluded ones & $\alpha_{\mathrm{c}}$ \\
\hline$C_{1}:$ Low & 58 & 196 & 138 & 152 & 0.30 \\
\hline$C_{2}:$ Medium & 62 & 181 & 119 & 167 & 0.34 \\
\hline$C_{3}:$ High & 71 & 196 & 126 & 151 & 0.36 \\
\hline
\end{tabular}
boundary sets. The lower and upper approximations and boundary sets of the product and market $(P M)$, functional $(F)$,
Table 4 Lower/upper approximations and boundary sets of the second stage.

team-based $(T B)$, combination $(C)$ sets, constituting the investment decision factors, were calculated.

In order to find the lower and upper approximations and boundary sets of the set for low, medium, and high investment decisions, subcategories (product/market, functional, team-based, and combination) of each investment decision is observed.

For the low investment decision, the set must have $P M_{1}, F_{1}$, $T B_{1}, C_{1}$ subsets, respectively.

For the medium investment decision, the set must have $P M_{2}$, $F_{2}, T B_{2}, C_{2}$ subsets, respectively.

For the high investment decision, the set must have $P M_{3}, F_{3}$, $T B_{3}, C_{3}$ subsets, respectively.

Lower and upper approximations and boundary sets were calculated according to investment decisions in different areas. Table 4 exhibits the number of elements of these sets and the certainty of the approximation.

According to the investment decision categories in different areas, the lower approximation and/or the upper approximation of each set is not equal to an empty set.

The boundary set is the difference between the upper approximation and the lower approximation for each decision set. Each decision set has a boundary region according to the low, medium, and high categories, and these boundary sets are not equal to the universal set. Therefore, each investment decision can be defined as a rough set.

For example, when $C_{*}\left(P M_{1}\right) \neq \varnothing$ and $C^{*}\left(P M_{1}\right) \neq U, P M_{1}$ set can be roughly defined in relation to $C$. When the lower and upper approximations are not equal, it can be stated that $C_{*}\left(P M_{1}\right) \neq C^{*}\left(P M_{1}\right)$ boundary set exists. The boundary region is a set of 124 elements.

The certainty of numerical approximation of a rough set is the ratio of the cardinality of the lower approximation to the cardinality of the upper approximation:

The certainty of the approximation for $P M_{1}$;

$$
\alpha_{c}\left(P M_{1}\right)=\frac{\left|C_{*}\left(P M_{1}\right)\right|}{\left|C^{*}\left(P M_{1}\right)\right|}=\frac{61}{85}=0.33
$$

Similarly, the certainty of the approximation is calculated for all levels of each investment decision dimension and is shown in the last column of Table 4. 
For the categories examined in the investment decisions, it is seen that female entrepreneurs have a 'high' level investment plan for all four investment decisions. The higher level of planning in the functional investment decision is more than in other categories. This is followed by a 'high' level of team-based investment decision and 'high' level of product-market investment decision. For these investment decisions and levels, the lower approximations, i.e. the granules that are certainly in the set, are more in number. The number of granules whose intersection with the set is not empty is also noticeable. Since the lower approximation granules are less than the upper approximation, the certainty of the approximation is low.

Calculation of rough set membership degrees. Membership degrees were calculated according to both stages of the research model and presented as two sub-titles. These sub-titles are given as calculation of first stage membership degrees and calculation of second stage membership degrees.

First stage membership calculation. The degree of membership of the granules into the set can also be defined using rough membership functions. Provided that the degree to which an $x$ element that is a member of $C$ is also a member of the $X$ set is shown as $\mu_{X}^{C}(x)$, hereby 'membership function' as follows:

$$
\mu_{X}^{c}(x)=\frac{|X \cap C(x)|}{|C(x)|}
$$

This formula can also be viewed as conditional probability.

The memberships of granules-that are formed according to six different characteristics namely; the marital status, age of the youngest child, education of the entrepreneur, duration of entrepreneurship, presence of active partner, entrepreneur density-to, $X_{1}$ : low, $X_{2}$ : medium, $X_{3}$ : high conflict levels of sets- that are defined for work-family conflict-were calculated. Likewise, the family-work conflict levels of these granules i.e. $Y_{1}$ : Low, $Y_{2}$ : Medium, $Y_{3}$ : High are shown in the same table. For example, in the G-85 granule that is not shown in Table 2, eight entrepreneurs answered following questionnaires $\{29,101,182$, $183,185,191,193$, and 308$\}$. Six features that these entrepreneurs give the same answers:

\section{Marital status: Married}

Youngest child: 6-18 years old

Education: University graduate

Entrepreneurship period: 6-10 years

Entrepreneur intensity: Medium

Active partner: None

There are eight elements in the granule. Two of these eight elements, four of these elements, and two of these elements experience 'low', 'medium', and 'high' level of work-family conflict respectively. In the same granule, three of these entrepreneurs' experience 'low', while five of these entrepreneurs' experience 'medium' level of family-work conflict. There are no women who experience 'high' level of family-work conflict in this granule. The memberships of this group that is designated as a granule to the six above defined sets were calculated:

$$
\begin{gathered}
\mu_{X_{1}}^{C}(x)=\frac{\left|X_{1} \cap C(x)\right|}{|C(x)|}=\frac{2}{8}=0.25 ; \mu_{X_{2}}^{C}(x)=\frac{4}{8}=0.50 ; \\
\mu_{X_{3}}^{C}(x)=\frac{2}{8}=0.25: \mu_{Y_{1}}^{C}(x) \frac{3}{8}=0.375 ; \\
\mu_{Y_{2}}^{C}(x)=\frac{5}{8}=0.625 ; \mu_{Y_{3}}^{C}(x)=\frac{0}{8}=0
\end{gathered}
$$

According to the six properties listed here, 226 granules are formed. In other words, it can be expressed that there are 226 different groups in terms of the six properties mentioned above. 167 of these granules have one element and the others have two or more elements.

\section{Table 5 Membership degrees of conflicts.}

\begin{tabular}{|llllll} 
Set & Element number & Ratio & Set & Element number & Ratio \\
\hline$X_{1}$ & 98.20 & 0.43 & $Y_{1}$ & 146.1789683 & 0.65 \\
$X_{2}$ & 60.91 & 0.27 & $Y_{2}$ & 64.10753968 & 0.28 \\
$X_{3}$ & 66.88 & 0.30 & $Y_{3}$ & 15.71349206 & 0.07 \\
Total & 226 & 1 & Total & 226 & 1 \\
\hline
\end{tabular}

\begin{tabular}{|lcllcl|}
\hline \multicolumn{7}{|l|}{ Table 6 Investment decision membership degrees. } \\
Set & Element number & Ratio & Set & Element number & Ratio \\
\hline$F_{1}$ & 50.34 & 0.22 & $T B_{1}$ & 71.45 & 0.32 \\
$F_{2}$ & 64.28 & 0.28 & $T B_{2}$ & 64.87 & 0.29 \\
$F_{3}$ & 111.38 & 0.49 & $T B_{3}$ & 89.69 & 0.40 \\
Total & 226 & 1 & Total & 226 & 1 \\
$P M_{1}$ & 71.01 & 0.31 & $C_{1}$ & 72.36 & 0.32 \\
$P M_{2}$ & 69.22 & 0.31 & $C_{2}$ & 73.32 & 0.32 \\
$P M_{3}$ & 85.77 & 0.38 & $C_{3}$ & 80.31 & 0.36 \\
Total & 226 & 1 & Total & 226 & 1 \\
\hline
\end{tabular}

After calculating these memberships for all granules, the number of elements (cardinality) of the six rough sets is calculated from the membership totals. According to this approach, the cardinalities of these six sets are shown together for the two types of conflict in Table 5. The intensity distributions in work-family and family-work conflict are shown in the same table.

Work-family conflict, which refers to family conflict due to work-related responsibilities, is low in $43 \%$ of 226 granules; $27 \%$ are medium and $30 \%$ are high. It was seen in the same granule that the distribution of negative status i.e. family-work conflict that emerges as a result of the fact that family-related responsibilities affect work performance, is 65\% low, $28 \%$ medium, and $7 \%$ high. In short, female entrepreneurs who prioritize their work experience less family-work conflict.

Calculation of second degree granules and investment decision membership degrees. In the study, 348 female entrepreneurs were collected in 226 groups with the same condition characteristics. These groups are granules. Four different types of investment decisions were considered in determining the opinions of these granules in investment decisions. These are functional, teambased, product and market, combination.

The entrepreneur was asked about the investment plans for the equipment. Low level investment planners $\left(F_{1}\right)$, medium level investment planners $\left(F_{2}\right)$, and high level investment planners $\left(F_{3}\right)$ were shown with their respective levels. With the questions related to their co-workers, investment plans about new staff needs and improvement of the existing staff were determined. On this subject, investment plans were shown as follows; $T B_{1}$ (low), $T B_{2}$ (medium), $T B_{3}$ (high). The entrepreneurs were asked about the product and market investments they consider about their sectors. Product development and new market entry related plans/thoughts were shown as follows; $P M_{1}$ (low), $P M_{2}$ (medium) and $\mathrm{PM}_{3}$ (high). Investment plans not included in these three investment decisions are also presented under the title of combination. In this category, $C_{1}$ (low), $C_{2}$ (medium), and $C_{3}$ (high) investment levels were determined. As in the above two groups of sets, the identity of each granule to these sets was also calculated and Table 6 was prepared.

Since the membership degree is a conditional probability value, the membership of the elements in the lower approximation set is 
Table 7 Work-family conflict and investment decisions intersection set number of elements.

\begin{tabular}{|c|c|c|c|c|c|c|c|c|c|c|c|c|}
\hline Work-family conflict & \multicolumn{3}{|c|}{ Functional } & \multicolumn{3}{|c|}{ Team-based } & \multicolumn{3}{|c|}{ Product and market } & \multicolumn{3}{|c|}{ Combination } \\
\hline Low & 15 & 23 & 41 & 23 & 23 & 29 & 22 & 25 & 26 & 21 & 27 & 27 \\
\hline High & 3 & 2 & 6 & 14 & 16 & 15 & 14 & 13 & 21 & 19 & 16 & 15 \\
\hline
\end{tabular}

Table 8 Family-work conflict and investment decisions intersection set number of elements.

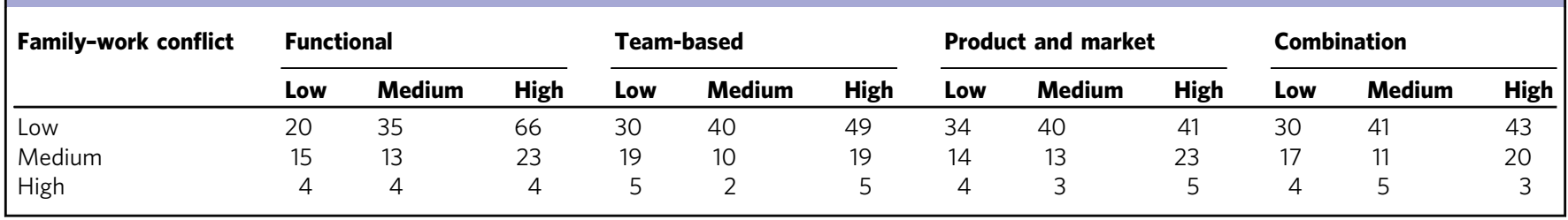

1. When the elements of the upper approximation sets include the lower approximation, their degree of membership can be 1 or range from 0 to 1 . If the membership is 0 , then it means it is outside the set. The elements that are in the boundary set for the decision property belong to the set with a value between 0 and 1 ; $0<\mu_{X}^{C}(x)<1$. Absolute, it other words $100 \%$ belonging is not possible in the boundary region.

As can be seen in Table 6, membership degrees' accounts show that the highest investment decision rate is the functional investment type in the "high" category. This is followed by a "high" investment plan for team-based and product-market investment decisions.

Correlation analysis of conflict and investment decisions. The conditions affecting the investment decision and the conditions affecting the work and family conflicts were analyzed separately. Functional, team-based, product and market, combination which are the sub-dimensions of our investment decisions and their relations with the two dimensions of conflicts (work-family and family-work) were examined via gamma measure developed and proposed by Leo Goodman and William Kruskal (1954).

In this subsection, first, intersection of lower approximation sets within the rough set of 226 granules of each decision property has been examined. The number of elements of these intersection sets is shown in Tables 7 and 8 below. In both tables, the number of female entrepreneurs with the "low" level of conflict is significantly higher. The "high" conflict levels can be seen to be quite low. It is seen that female entrepreneurs in this category are relatively evenly distributed to "low", "medium" and "high" level investment decisions.

Gamma coefficient is a proposed measure of relationship for sequential scale, and it is used to optimize the prediction. $X$ and $Y$ variables' values are shown as follows; $x_{1} \leq x_{2} \leq \cdots \leq x_{i} ; y_{1} \leq$ $y_{2} \leq \cdots \leq y_{j}$. There is no assumption of continuity. There is the assumption of symmetry. With the gamma coefficient, the likelihood that two randomly selected variables move in a similar or different manner is evaluated (Goodman and Kruskal, 1954).

The gamma coefficient can be calculated with frequencies. The number of changes in the same direction $\left(N_{c}\right)$, the number of changes in the opposite direction $\left(N_{\mathrm{d}}\right)$, the number of changes in one of the variables when there is no change in the other, or the absence of change in both variables $\left(N_{\mathrm{t}}\right)$ is shown. Total frequency is expressed as ' $n$ '. The formulas and gamma coefficient
Table 9 Gamma coefficient values for investment decisions and conflicts.

\begin{tabular}{lll} 
Investment decision & Work-family conflict & Family-work conflict \\
& $\boldsymbol{\gamma}$ & $\boldsymbol{\gamma}$ \\
\hline Functional & -0.016 & -0.121 \\
Team-based & -0.009 & -0.067 \\
Product and market & 0.032 & 0.046 \\
Combination & -0.041 & -0.040 \\
\hline
\end{tabular}

calculation of these values are as follows (Goodman and Kruskal, 1954):

$$
\begin{gathered}
N_{\mathrm{c}}=2 \sum_{i} \sum_{j} f_{i j}\left(\sum_{i^{l}>i} \sum_{j^{l}>j} f_{i}^{l} j^{l}\right) \\
N_{\mathrm{d}}=2 \sum_{i} \sum_{j} f_{i j}\left(\sum_{i^{l}>i} \sum_{j^{l}>j} f_{i}^{l} j^{l}\right) \\
N_{\mathrm{t}}=\sum_{i} f_{i+}^{2}+\sum_{j} f_{+j}^{2}-\sum_{i} \sum_{j} f_{i j}^{2} \\
\gamma=\frac{N_{\mathrm{c}}-N_{\mathrm{d}}}{n^{2}-N_{\mathrm{t}}}
\end{gathered}
$$

For the frequencies given in Tables 7 and 8, Gamma coefficient values are presented in Table 9.

As shown in Table 9, the correlation between all subdimensions of investment decisions and work-family and family-work conflicts is close to 0 . There is no relationship between these variables. The fact that family conflict at work or work-related conflict in the family is experienced affects female entrepreneurs' investment decisions. These correlations were also calculated by Kendall's tau-b formula which was developed for sequential scale and again no significant correlation was found. Assuming the categories on a nominal scale, the lambda measurements suggested by Goodman and Kruskal were also tested. This measure is a measure of the explainability of the other variable while the marginal distribution (probability or frequency distribution) of one of the row or column variables is known. This is the coefficient which shows a cause-effect relationship that can 
be called as the equivalent of the regression interpretation in numerical scales at nominal scale. When the values of this coefficient were calculated, no significant result was found. Because, when we look at the distribution of frequencies or ratios in a double-entry table, it is seen in Tables 7 and 8 that weights are collected in a row or a column. The fact that there is no correlation (especially measured by gamma coefficient) between the variable indicating the work-family or family-work conflict and the willingness to make investment decisions of various types is not sufficient to say that these variables are independent of each other. According to Goodman and Kruskal, if these variables are independent of each other, gamma coefficient is 0 . However, it is not correct to say the opposite. In other words, if the gamma coefficient is 0 , we cannot talk about the independence of the variables. As a result, by examing data (when we consider one of these variables as the cause and the other as the effect), it can be stated that the cause variable has no impact of reducing prediction errors on the effect variable (lambda coefficient). In other words, it would be useless to look for a regressive relationship between these variables.

\section{Conclusion}

In this study, that aims to examine women as entrepreneurs along with their other roles and responsibilities expected by the society, a face-to-face survey was conducted with 348 female entrepreneurs and the dilemmas and their investment decisions were examined with various questions asked in this survey. The perception of society and the workplace tasks of women as entrepreneurs create a conflicting environment. This conflict is twofold. It is in the form of a tension in workplace due to the problems in family and a tension in family due to the problems in workplace. If this tension is excessive, then these two cannot coexist. In other words, excessive conflict experiencing women were not in this study since they eventually have to choose one or the other.

We investigated the answers of three questions. The first research question is "Are the responsibilities of female entrepreneurs' in both business and family decisive for conflict that they experience?". In this sense, most of the women involved in the study are at a low level of conflict. Our study was conducted in the provinces with the lowest gender inequality. According to the gender equality report card, Istanbul is the province with the lowest gender inequality. Bursa ranks second in this list, Yalova ranks seventh and Kocaeli ranks tenth (Urul, 2016). Therefore, the results of our research do not represent the whole of our country, but cover the region with the highest economic development and the lowest gender inequality.

In this research, there are various entrepreneurs and various investment areas. Rough sets are formed with a classification that accepts investors with the same characteristics as units (granules). Here, rough sets are defined according to the various decision situations of these communities showing the same characteristics. Despite this classification, 226 granules were formed due to the large number of dissimilarities among the entrepreneurs, most of which appeared as single-element.

Cronbach's alpha statistics were used to determine the reliability of the questions we received from tried manner scales. After this stage, rough-sets analysis and Goodman-Kruskal and Kendall's correlation coefficients were measured.

In order to measure second research question, that is: "Are the responsibilities of female entrepreneurs' in both business and family decisive for their investment decision?" Firstly, the rough set analysis, which accepts the entrepreneurs with the same characteristics as units, was performed. The female entrepreneurs who participated in our study were classified by rough set theory.
Factors related to entrepreneurial roles of female entrepreneurs (active partnership status, entrepreneurial intensity, duration of entrepreneurship) and factors related to family roles (marital status, education, age of youngest child) were examined. These factors were clustered for work-family and family-work conflicts and for functional, team-based, product-market and combination dimensions, which expressed investment decisions. Entrepreneurship intensity, level of conflict and investment decisions are classified as low, medium and high considering the median of the total of the answers given. Conflict and investment decisions formed the decision property, while qualifications formed factors about family and entrepreneurship. Firstly, granules were calculated in which female entrepreneurs of the same qualifications were classified. Then, the membership functions of the 226 granules to decision properties were determined. According to the membership functions, it was found that family-work conflict was lower than work-family conflict. Although this result confirms the findings of Frone et al. (1992a, 1992b), there was not a three-fold difference between the two aspects of conflict. It is more likely that job-related responsibilities affect family performance. Family responsibilities are less likely to affect job performance. This means that female entrepreneurs see their work as a priority in their lives. Membership ratings for investment decisions were detected approximate for each level. However, high level planning of the functional investment decision is more prominent than the other investment decisions (49\%). So, contrary to the DuRietz and Henrekson (2000) and Sexton (1989) female entrepreneurs in Turkey are passionate about investment.

Third research question is "What is the relationship between conflict level that they live both in business and family and their investment decision?". The relationship between conflict and investment decision was also examined. There was no significant relationship between these two factors. In this study conducted on an ordinary scale, in the cross-product tables, there was no significant order correlation due to the addition of weighted frequencies in a row or a column. The most striking finding here is that female entrepreneurs who participated in our study experienced predominantly low levels of conflict. It is seen that female entrepreneurs in this category are relatively evenly distributed to "low", "medium", and "high" level investment decisions. In the light of Diagos ${ }^{1}$ question, female entrepreneurs who did not participate in the research could not express themselves within the scope of this study. This result suggests that women, who cannot find the balance between their job and family, in other words living in conflict at a "high" level, cannot think of entrepreneurship. This is also an important issue for Turkish Government to address. Since, there is great potential of entrepreneurship, by reducing conflict factors for female entrepreneurs, it is possible to increase employment rate in Turkey. It should be noted that in Turkey, microcredits are too limited and family support mechanisms (like support for child care) are quite poor. By making appropriate regulations, it is possible to increase number of entrepreneurs. For example, Wang and Lin (2019) found that child care facilities increase probability of being entrepreneur in some countries like China.

Thanks to previous studies, family and household responsibilities are known to have an impact on female entrepreneurs' investment decisions (Carter and Ram, 2003; Aldrich and Cliff, 2003; Türkonfed, 2014). In our study, since female entrepreneurs experience low level of conflict, family-based responsibilities do not have an impact on investment decisions. On the contrary to control mechanism (Cliff, 1998), they are eager to invest in their enterprises. This may be stemmed from the fact that, when they stop investing, they cannot survive in business area.

Consequently, the study can be summarized in two dimensions. These include the analysis of female entrepreneurs, 
work-family, family-work conflicts and investment decisions with rough sets; the relationship between conflict and investment decisions.

\section{Limitations and future research}

Studies which generally tackle entrepreneurship issue is on a dramatic rise (Katz, 2003), female entrepreneurship issue come into question lately. Also female entrepreneurs research has not reached to desired level so far. Only $7.5 \%$ of entrepreneurship studies have been dedicated to female entrepreneurship which are traced on Web of Science until February 2016. So, this research subject will positively contribute to the general entrepreneurship theory.

Contrary to the most of the studies on female entrepreneurs, this study is not comparing female entrepreneurs with their male counterparts. It is clear that entrepreneurship might differ for each gender (Hisrich and Peters, 2002; Hisrich and Ozturk, 1999; Brush et al., 2004). So, on behalf of making a different comparison, we, in our study, investigated female entrepreneurs separately.

Our study was conducted in the provinces with the lowest gender inequality. So, next study might cover a much wider geographical area in Turkey, and some comparisons can be made between different regions of the country.

Following this study, a separate study might be conducted with female entrepreneurs for a correlation between conflict levels and investment intensity. Indirect questions for such an inquiry may be considered. A separate study may also be carried out with unsuccessful (business-wise) female entrepreneurs. In recent years, the studies on "Mompreneurship" have become widespread. In this sense, as a more narrowed area than women's entrepreneurship, this issue may be worth investigating.

\section{Data availability}

All data analyzed or generated are available in the paper.

Received: 18 October 2019; Accepted: 12 May 2020;

Published online: 24 June 2020

\section{Note}

1 According to M.T.Cicero's narrative, some picture tablets are shown to Diagoras, who was an atheist. On the tablets are pictures of the believers praying and surviving the shipwreck. Diagos: "Where are the pictures of those who pray and then drown? (Talep, 2007).

\section{References}

Agarwal S, Lenka U (2015) Study on work-life balance of women entrepreneursreview and research agenda Ind Commer Train 47(7):356-362

Ahmad S, Skitmore M (2003) Work-family conflict: a survey of Singaporean workers Singap Manag Rev 25(1):35-52

Aldrich HE, Cliff J (2003) The pervasive effects of family on entrepreneurship: toward a family embeddedness perspective. J Bus Ventur 18:573-596

Armutlulu İ (2014) Belirsizlik ve Fazi Aritmetiği Sosyal Bilimlerin Dili. Alfa Press, İstanbul

Aycan Z (2013). Türkiye'de Meslek Sahibi Kadınların Kariyer Gelişimi. In: Bekman S, Aksu-Koç A (eds) İnsan Gelişimi, Aile ve Kültür: Farklı Bakış Açıları. Koç Üniversitesi Yayınları, İstanbul, pp 333-347.

Bagger J, Li A (2012) Being important matters: the impact of work and family centralities on the family-to-work conflict-satisfaction relationship Hum Relat 65(4):473-500

Bedian AG, Burke BG, Moffett RG (1988) Outcomes of work-family conflict among married male and female professionals J Manag 14(3):475-491

Brush CG, Bruin A, Gatewood EJ, Henry C (2010) Introduction: women entrepreneurs and growth. In: Brush CG, Bruin A, Gatewood EJ, Henry Colette (eds) Women entrepreneurs and the global environment for growth. Edward Elgar Publishing, pp 2-16
Bruyat C, Julien P (2000) Defining The Field of Research in Entrepreneurship. J Bus Venturing 16:165-180

Byron K (2005) A meta-analytic review of work-family conflict and its antecedents. J Vocat Behav 67:169-198

Brush CG, Carter NM, Gatewood EJ, Greene EJ, Hart MM (2004) Clearing the hurdles women building high-growth business. Metro Voice Publishing.

Caputo RK, Dolinsky A (1998) Women's choice to pursue self-employment: the role of financial and human capital of household members J Small Bus Manag 36(3):8-17

Carlson DD, Kacmar KM, Williams LJ (2000) Construction and initial validation of a multidimensional measure of work-family conflict. J Vocat Behav 56:249-276

Carree MA, Thurink AR (2003) The impact of entrepreneurship on economic growth. In: Acs ZJ, Audretsch DB (eds.) Handbook of entrepreneurship research. Kluwer Academic Publishers, Boston/Dordrecht/London, pp 437-471

Carter S, Ram M (2003) Reassessing portfolio entrepreneurship: towards a multi disciplinary approach Small Bus Econ 21(4):371-380

Casson M, Bernard Y, Anuradhaand B, Nigel Wadeson W (Eds) (2006) Oxford handbook of entrepreneurship. Oxford University, Oxford

Cliff JE (1998) Does one size fit all? Exploring the relationship between attitudes towards growth, gender, and business size J Bus Ventur 13(6):523-542

Davis AE, Shaver KG (2012) Understanding gendered variations in business growth intentions across the life course. Entrep Theory Pract 36:495-512

Delmar F (1996) Measuring growth: methodological considerations and empirical results. In: Davidson P, Delmar F, Wiklund J (eds) Entrepreneurship and the growth of firms. Edward Elgar Publishing, pp 62-84.

DuRietz A, Henrekson M (2000) Testing the female underperformance hypothesis Small Bus Econ 14(1):1-10

Eagle BW, Miles EW, Icenogle ML (1997) Interrole conflicts and the permeability of work and family domains: are there gender differences? J Vocational Behav 50:168-184

Eagle BW, Icenogle ML, Maes JD, Miles EW (1998) The importance of employee demographic profiles for understanding experiences of work-family interrole conflicts J Soc Psychol 138(6):690-709

Eby LT, Casper WJ, Lockwood A, Bordeaux C, Nrinley A (2005) Work and family research in IO/OB content analysis and review of the literature (1980-2002). J Vocat Behav 66:124-197

Frone MR, Yardley JK, Markel KS (1997) Developing and testing an integrative model of the work-family interface. J Vocat Behav 50:145-167

Frone MR, Russell M, Cooper ML (1992) Antecedents and outcomes of work-family conflict: testing a model of the work-family interface J Appl Psychol 77(1):65-78

Frone MR, Russell M, Cooper ML (1992) Prevalence of work-family conflict: are work and family boundaries asymmetrically permeable? J Organ Behav 13 (7):723-729

Gatewood. EJ, Shaver KG, Gartner WB (1995) A longitudinal study of cognitive factors influencing start-up behaviors and success at venture creation. J Bus Ventur 10:371-391

Goodman LA, Kruskal WH (1954) Measures of association for cross classifications J Am Stat Assoc 49(268):732-764

Greenhaus JH, Beutell NJ (1985) Sources of conflict between work and family roles Acad Manag Rev 10(1):76-88

Greenhaus JH, Powell GN (2002) When work and family collide: deciding between competing role demnas. Organ Behav Hum Decis Process 90:291-303

Gundry LK, Welsch HP (2001) The ambitious entrepreneur: high growth strategies of women-owned enterprises. J Bus Ventur 16:453-470

Gutek BA, Searle S, Klepa L (1991) Rational versus gender role explanations for work-family conflict J Appl Psychol 76(4):560-568

Hill EJ (2005) Work-family facilitation and conflict, working fathers and mothers, work-family stressors and support J Fam Issues 26(6):793-819

Hisrich R, Brush C (1984) The woman entrepreneur: management skills and business problems. J Small Bus Manag 22(1):30-37

Hisrich RD, Brush CG (1985) Women \& minority Entrepreneurs: A comparative analysis. In: Hornaday J, Shills E, Timmons J, Vesper K (eds) Frontier of Entrepreneurship Research, Boston Center for Entrepreneurial Studies, Wellesley, MA, pp 566-587

Hisrich R, Brush C (1986) The woman entrepreneur starting, managing and financing a successful new business. Lexington Books, Lexington

Hisrich RD, Brush C (1987) Women entrepreneurs: A longitudinal study. In Churchill N, Hornaday J, Kirchhoff B, Krasner O, Vesper K (Eds) Frontiers of entrepreneurship research. Babson College, Boston, MA, pp 187-199

Hisrich DR, Öztürk SA (1999) Women entrepreneurs in a developing economy J Manag Dev 18(2):114-124

Hisrich DR, Peters MP (2002). Entrepreneurship. 5th edn. McGraw-Hill

Hutt R (2015). There are the top 5 issues facing working women in G20 countries. World Economic Forum. https://www.weforum.org/agenda/2015/10/theseare-the-top-5-issues-facing-working-women-in-g20-countries/? 
utm_content $=$ buffer9f377\&utm_medium $=$ social\&utm_source $=$ twitter. com\&utm_campaign=buffer. Accessed 13 Oct 2015

Jennings JE, Brush CG (2013) Research on women entrepreneurs: challenges to (and from) the broader entrepreneurship literature? Acad Manag Ann 7.1:663-715

Jian L, Liu S, Lin Y (2011) Hybrid rough sets and applications in uncertain decision-making. CRC

Karadal H, Kaygın E (2013) Kadın Girişimciliği. In: Karadal Himmet (Ed) Girissimcilik. Beta Yayınları, İstanbul, pp 245-258

Katz JA (2003) The chronology and intellectual trajectory of American Entrepreneurship education 1876-1999. J Bus Ventur 18:283-300

Kauffman Foundation (2012) The ascent of America's high-growth companies, an analysis of the geography of entrepreneurship. Ewing Marion Kauffman Foundation

Kuratko DF, Hodgetts RM (1995) Entrepreneurship, 3rd edn. The Dreyden Press, Orlanda

McGowan P, Redeker CL, Cooper SY, Greenan K (2012) Female entrepreneurship and the management of business and domestic rules: motivations, expectations and realities Entrep Reg Dev 24(1-2):53-72

Morris MH, Miyasaki NN, Watters CE, Coombes SM (2006) Dilemma of growth: understanding venture size choices of women entrepreneurs J Small Bus Manag 44(2):221-244

Nayır DZ (2008) İși ve Ailesi Arasındaki Kadın: Tekstil ve Bilgi İșlem Girişimcilerinin Rol Çatışmasına Getirdikleri Çözüm Stratejileri Ege Akad Bakış 8(2):631-650

Netemeyer RG, Boles JS, McMurrian R (1996) Development and validation of work-family conflict and family-work conflict scales J Appl Psychol 81(4): $400-410$

Noor NM (2004) Work-family conflict, work and family role salience and women's well being J Soc Psychol 144(4):389-405

Orser B, Hogarth-Scott S (2002) Opting for growth: gender dimensions of choosing enterprise development Can J Adm Sci 19(3):284-300

Pagliani P, Chakraborty M (2008) Trends in Logic 27 a geomethry of approximation rough set teory: logic, algebra and topology of conceptual patterns. Springer, Warsaw

Parasuraman S, Greenhaus JH, Granrose CS (1992) Role stressors, social support, and well-being among two-career couples. J Organ Behav 13:339-356

Parasuraman S, Simmers CA (2001) Type of employment, work-family conflict and well-being: a comparative study. J Organ Behav 22(5):551-568

Pawlak Z (1982) Rough sets. Int J Inf Comput Sci 11:341-356

Pawlak Z, Slowinski R (1994) Rough set approach to multi-attribute decision analysis. Eur J Oper Res 72:443-459

Pawlak Z (1997) Rough set approach to knowledge-based decision support. Eur J Oper Res 99:48-57

Pawlak Z (1991) Rough sets theoretical aspects of reasoning about data. Kluwer, Dordrecht

Pawlak Z (1998) A treatise on rough sets. In: Peters JF, Skowron A (eds.) Transactions in rough sets IV. Springer, Berlin-Heidelberg-New York, pp 1-17

Pawlak Z (2000) Rough sets and decision analysis INFOR 38(3):132-144

Pawlak Z (2004) Some issues on rough sets. In: Peters JF, et al., (Eds) Transactions on rough sets I, LNCS 3100. Springer Verlang, Berlin Heidelberg, pp 1-58

Pistrui D (1999) Growth Intention and Expansion Plans of New Entrepreneurs in Transforming Economies: An Investigation into family Dynamics, Entrepreneurship, and Enterprise Development. Unpublished PhD Thesis. Universidad Autonoma de Barcelona, Spain

Pistrui D, Lucia SD (2003) Growth intentions and expansion plans of Venezuela's entrepreneurs. Alfred University. Collage of Business. Centre for Family Business and Enterpreneurial Enterprise

Rembulan CL, Rahmawati KD, Indudewi FYR (2017) Work-Family Conflict of Women Entrepreneurs and Women Employees. ANIMA Indones Psychol J 31:111

Schmitt N, Colligan MJ, Fitzgerald M (1980) Unexplained physical symptoms in eight organisations: individual and organisational analyses. J Occup Psychol 53:305-317
Schumpeter J (1947) Theoretical problems of economic growth. In: Clemence R (Ed) Essays of J.A. Schumpeter. Addison-Wesley Press, Cambridge, pp 227-235

Sexton DL (1989) Research on women's business owners. In: Hagen O, Rivchun C, Sexton DL (Eds) Women owned businesses. Praeger, New York, pp 135-150

Smith-Hunter AE (2006) Women entrepreneurs across racial lines: issues of human capital, financial capital and network structures. Edward Elgar Publishing, Massachusetts, pp 261-272

Talep NN (2007) Siyah Kuğu (Black Swarn). 4 edn. İstanbul: Varlık Yayınları

Thebaud S (2015) Business as Plan B: institutional foundations of gender inequality in entrepreneurship across 24 industrialized countries Adm Sci Q 60 (4):671-711

Tripathy BK (2009) Rough sets on fuzzy approximation spaces and intuitionistic fuzzy approximation spaces. In: Abraham A, Falcon R, Bello R (eds) Rough set theory: a true landmark in data analysis, Springer Verlag, Berlin, pp 3-44

Türkonfed (2014). İs Dünyasında Kadın Cilt 2. In: Bakırcı K, Karadeniz O, Yılmaz H, Lewis N, Durmaz N (eds). Sis Matbaacllık, İstanbul

Ufuk H, Özgen Ö (2001) Interaction between the business and family lives of women entrepreneurs in Turkey. J Bus Ethics 31:95-106

Urul AK (2016) Social gender equality report card for 81 provinces. TEPAV. Available from https://www.tepav.org.tr/upload/files/14581420298.81_Ilin_Toplumsal_Cinsiyet_Esitligi_Karnesi.pdf

Van Praag CM, Versloot PH (2007) What is the value of entrepreneurship? A review of recent research Small Bus Econ 29(4):351-382

Van Veldhoven MJPM, Beijer SE (2012) Workload work-to-family conflict and health: gender differences and influence of private life context J Soc Issues 68 (4):665-683

Wang Q, Lin M (2019) Work-family policy and female entrepreneurship: evidence from China's subsidized child care program. China Econ Rev 54:256-270

Welter F, Smallbone D (2011) Institutional perspectives on entrepreneurial behavior in challenging environments. J Small Bus Manage 49:107-125

Winn J (2004) Entrepreneurship: not an easy path to top management for women Women Manag Rev 19(3):143-153

\section{Competing interests}

The authors declare no competing interests.

\section{Additional information}

Correspondence and requests for materials should be addressed to G.B.B.

Reprints and permission information is available at http://www.nature.com/reprints

Publisher's note Springer Nature remains neutral with regard to jurisdictional claims in published maps and institutional affiliations.

Open Access This article is licensed under a Creative Commons Attribution 4.0 International License, which permits use, sharing, adaptation, distribution and reproduction in any medium or format, as long as you give appropriate credit to the original author(s) and the source, provide a link to the Creative Commons license, and indicate if changes were made. The images or other third party material in this article are included in the article's Creative Commons license, unless indicated otherwise in a credit line to the material. If material is not included in the article's Creative Commons license and your intended use is not permitted by statutory regulation or exceeds the permitted use, you will need to obtain permission directly from the copyright holder. To view a copy of this license, visit http://creativecommons.org/ licenses/by/4.0/

(c) The Author(s) 2020 